\title{
Pertahanan Israel:Awal Buramnya Masa Depan Perdamaian di Timur Tengah
}

\author{
Abdul Rahman \\ Alumni Jurusan Hubungan Internasional, Fakultas IImu Sosial dan Politik, Universitas \\ Muhammadiyah Yogyakarta \\ Kampus Tamantirto, Bantul 55183 \\ Email:abdulrah_man@yahoo.com
}

\begin{abstract}
Even though just established on 1948, the power or Israel Defense cannot be underestimated. The Defense Policy was formed before Israel established. From the Jewish villages or Yishuv, the forming of semi Defense Forces already done. Haganah formation became the main component of Israel Defense Force formation (IDF).After Israel Defense is strong, then the target of IDF formation is to do a political pressure in gaining land. It proved on 1967, Israel success in the occupied Arab countries area which then claimed as their country. From this moment, Israel is doing maneuvers politic to seize Palestine land, then switched to Israel country.

Keywords:Israel Defense Forces (IDF), maneuver politic, zionis
\end{abstract}

\begin{abstract}
Abstrak
Sekalipun baru berdiri tahun 1948, kekuatan pertahanan Israel tidak bisa dianggap remeh. Kebijakan pertahanan sudah dibentuk sebelum berdiri Negara Israel. Dari perkampungan-perkampungan Yahudi atau Yishuv, pembentukan pasukan pertahanan semi terlatih sudah dilakukan. Pembentukan Haganah menjadi komponen utama pembentukan Israel Defense Force (IDF).Setelah Pertahanan Israel kuat maka sasaran pembetukan IDF adalah melakukan tekanan politik untuk memperoleh tanah. Terbukti pada tahun 1967 Israel berhasil menduduki wilayah negaranegara Arab kemudian secara sepihak diakui sebagai negaranya. Dari sinilah Israel melakukan politik maneuver guna merebut tanah Palestina kemudian diganti menjadi Negara Israel.

Kata Kunci:Pasukan Pertahanan Israel (IDF), politik maneuver, zionis
\end{abstract}

\section{PENDAHULUAN}

Setelah kongres Zionis pertama tahun 1879, kaum Yahudi di Rusia sudah berpikir untuk mendirikan organisasi sukarelawan. Organisasi sukarelawan bertujuan untuk mendukung langkah menuju ke wilayah Palestina. Organisasi pertama yang didirikan ini adalah Hehaluzt (Organisasi Pemuda Yahudi) berdiri tahun 1908 (Walter Laqueur, 1972:327). Organisasi ini mempunyai tujuan membangkitkan semangat kaum Yahudi datang ke Palestina dan tinggal di sana. Adanya tujuan politik yang ingin dicapai dalam bentuk mendapatkan tanah di Palestina menjadi gambaran nyata mengenai visi dan misi organisasi Yahudi. Pada waktu berikutnya, berdasarkan aktiviktas yang dilakukan Hehaluzt, organisasi-organisasi Yahudi berorientasi berdasarkan Hovevei Zion (Lover of Zion).
Pemuda-pemuda keturunan Yahudi sejak tahun 1890-an sudah mendirikan organisasi-organisasi yang dekat dengan politik. Namun organisasi yang didirikan lebih banyak melakukan aktivitas dalam bentuk kampanye politik untuk menyatukan keturunan Yahudi. Kampanye dilakukan lebih bersifat membakar semangat agar jangan lupa terhadap tanah air Yahudi. Beberapa organisasi, berusaha melaksanakan kegiatan politik setelah mendapat dukungan dari Persatuan Zionis. Cara yang dilakukan adalah melaksanakan politik pembangkangan terhadap penguasa Palestina.

Dalam deklarasinya yang pertama, Persatuan Zionis menegaskan bahwa organisasi yang kita dirikan berjanji untuk melindungi kaum Yahudi masuk ke Palestina (Rosemary Sayigh, 1979:9). Perlindungan dilakukan dengan cara memberi jaminan mendirikan unit-unit 
pertahanan Zionis yang ditujukan untuk maksud melihat, mengamati kemudian membeli tanah dari penduduk Palestina.

Setelah kaum Yahudi banyak berdatangan dari Rusia ke Palestina, mereka membentuk gerakan bawah tanah seperti Jewish Legion dan Gdudim, anggotanya terdiri dari sukarelawan Yahudi yang siap berjuang untuk kesatuan kaum Yahudi. Gerakan Zionis yang menganut faham Zionis-Sosialis memainkan peran sebagai pasukan keamanan terhadap Kibbutz-kibbutz atau perkampungan baru Yahudi (Amos Perlmutter, 1978:9). Berdasarkan aktivitas gerakan, mereka diberi nama dengan Hashomer. Gerakan semacam ini kebanyakan lahir dan berkembang karena ada kelompok masyarakat pekerja Yahudi di Rusia dan dikenal sangat revolusioner. Salah satunya adalah Hashomer (Richard Deacon, 1977:23).

Hashomer Hatzair sepenuhnya mengambil ideologi Zionis sebagai panduan dan menitikberatkan pada keperluan kaum Yahudi supaya bisa memulihkan kehidupan dengan mengganti struktur ekonomi mereka dan menjadi pekerja kebun yang akan tinggal di Palestina dan bekerja sebagai peladang. Pola pikir mereka lebih dipengaruhi pemikiran sosialis yang ada dan mereka bermimpi mengadakan aktivitas-aktivitas di tempat tinggal baru yang terdiri dari suatu masyarakat berdasarkan keadilan sosial dan persamaan ras (http://www.us-israel.org).

\section{PEMBAHASAN}

\section{GERAKAN BAWAH TANAH}

Setiap tahun banyak kaum Yahudi datang ke Palestina. Ada yang datang secara resmi karena telah mendapat perlindungan dari tentara Inggeris. Sebagian besar lagi datang dengan cara tidak resmi. Mereka masuk ke Palestina pada waktu malam hari untuk menghindar dari kontrol tentara Inggeris. Selain sudah di jaga ketat, kedatangan kaum Yahudi ke Palestina melalui suatu rencana khusus yang dilakukan gerakan bawah tanah. Tidak heran jadinya kaum Yahudi yang masuk ke Palestina menggunakan cara-cara penyusupan yang dilakukan pada malam hari dan jumlahnya lebih besar dibanding cara resmi.

Setelah sampai di Palestina para pendatang Yahudi membeli tanah dengan harga mahal dari penduduk lokal untuk membangun Yishuv-Yishiv (perkampungan Yahudi) kemudian membangun kawasan pertanian secara besar-besaran untuk menghasilkan bahan makanan (Don Peretz, 1996:119). Secara sistematis, gerakan bawah tanah Yahudi yang mendatangkan kaum Yahudi disebut dengan Aliyah. Identitas ini diberikan untuk maksud melindungi pendatang Yahudi dengan undang-undangan masyarakat. Pengaturan undangundang mengenai kedatangan kaum Yahudi dibuat oleh kaum Yahudi sendiri (Tareq Y. Ismael, 1991:259).

Aliyah pertama berlangsung pada tahun 1880-an. Kedatangan kaum Yahudi dari Eropa ke Palestina dengan alasan untuk beribadah. Jumlah kaum Yahudi yang datang pada aliyah pertama kira-kira 25,000 orang. Tempat pertama pendaratan kapal-kapal Zionis berada di Jaffa tepatnya pada tanggal 7 Juli 1882. Setelah masuk ke Palestina, mereka membangun 20 daerah pertanian baru dengan luas tanah 90, 000 hektar (Ian J. Bickerton and Carla L. Klausner, 1991:21). Selanjutnya, pemukiman Yahudi di perkampungan Jaffa pada tahun 1926 membangun sekolah pertanian perempuan pertama (Moshe Dayan, 1974:73).

Aliyah kedua tahun 1904 sampai 1913 dan mendatangkan sebanyak 40,000 orang. Aliyah ketiga tahun 1919 sampai 1923 mendatangkan sebanyak 35,000 orang. Aliyah keempat tahun 1924-1928 mendatangkan sebanyak 67,000 orang dan Aliyah kelima tahun 1929 sampai 1939 mendatangkan sebanyak 250,000 orang. Semua data ini dicatat berdasarkan jumlah orang Yahudi yang masuk ke Palestina (Moshe Dayan, 1974:259-260) Mereka datang sesuai rencana yang dibuat oleh Jewish Agency. Setiap kelompok Yahudi yang datang atau disebut dengan Hovevei Zion dan terdiri dari kelompok-kelompok. Tiap-tiap kelompok beranggota empat belas orang. Di antara empat belas orang tersebut, satu di antaranya mesti seorang wanita. Tujuannya supaya wanita dapat mempersiapkan bekal untuk keperluan laki-laki dan dibina menjadi pekerja ladang.

Masuknya kaum Yahudi ke Palestina mendapat pengawalan ketat dari kaum Yahudi lainnya yang sudah lebih dulu tinggal di sana. Jaminan keselamatan dan keamanan dalam bentuk kekuatan sangat berperan membantu kaum Yahudi yang baru datang untuk 
menghindar dari tekanan penduduk Palestina. Banyak kaum Yahudi sudah lebih dulu tinggal di perkampungan-perkampungan dan mendapatkan latihan mengenai dasar-dasar militer. Tugas yang dilakukan bukan hanya menyangkut keselamatan dan keamanan saja tetapi juga politik kawasan yang diperkirakan menjadi hambatan masuknya kaum Yahudi.

Kebanyakan mereka yang turut serta dalam gerakan bawah tanah telah mendapat latihan di bidang militer seperti (i) memberi pengawalan terhadap kampung Yahudi (ii) melakukan tekanan terhadap pihak Palestina sekiranya Yishuv diserang dan (iii) melakukan mobilisasi terhadap kekuatan-kekuatan kaum Yahudi yang tersebar di berbagai Yishuv. Walaupun jarak antara satu Yishuv dengan Yishuv lainnya berjauhan tetapi karena ada kebersamaan dan komunikasi, mereka mampu memberi jaminan keamanan secara kolektif.

Pelatihan terhadap anggota baru diberikan dengan cara pembekalan tehnik-tehnik ketentaraan oleh kaum Yahudi yang sudah berpengalaman perang di negaranegara Eropa. Tentara-tentara Yahudi yang baru mendapat pelatihan disatukan dalam sebuah pasukan dan di beri nama Brigade Yahudi. Setelah memiliki kemampuan militer, tentara yang tergabung dalam Brigade Yahudi dipecah lagi untuk membentuk satu pasukan khusus. Tujuannya agar dapat menahan amarah penduduk Palestina terhadap perkampungan Yahudi. Apalagi diketahui, secara terang-terangan penduduk Palestina tidak mau menerima keberadaan kaum Yahudi di kawasannya. Akibatnya konflik dan perang seporadis antara penduduk Palestina dengan gerakan bawah tanah Yahudi di kawasan-kawasan yang berdekatan tidak dapat dielakkan. Masyarakat Yahudi yang tinggal di Yishuv dan penduduk Palestina sering bertentangan dan tidak jarang berakibat bentrokan fisik dan kontak senjata.

Untuk memberi jaminan keamanan terhadap Yishuv, kaum Yahudi mendirikan lagi satu gerakan bawah tanah yang diberi nama Histadrut. Histadrut berfungsi sebagai pertahanan dan melindungi Kibbutz. Dari Histadrut terdapat suatu gerakan lainnya yaitu Haganah. Haganah berada dibawah komando bawahan dari Histadrut (Amos Perlmutter, 1978:10). Sewaktu Haganah didirikan, Histadrut sudah merencanakan suatu kerjasama untuk memasukkan kaum Yahudi ke Palestina. Tahun 1920 Histadrut mempunyai anggota sebanyak 4,400 orang dan pada tahun 1927 bertambah 2,200 orang lagi (Walter Lagueur, 1972:317). Penambahan jumlah ini untuk memberi dukungan terhadap gerakan bawah tanah lainnya. Haganah sendiri memberi perhatian terhadap pertahanan masyarakat Yahudi.

Tentara rahasia Yishuv di Eretz Yisrael berdiri dari tahun 1920 hingga 1948. Kerusakan di kawasankawasan Palestina dalam tahun 1920 dan 1921 memperkuat pandangan bahwa kaum Yahudi tidak bisa berharap terhadap pemerintah Inggeris, Yishuv perlu mendirikan satu pasukan pertahanan yang bebas dan tidak terikat kepada pemerintah asing. Pada bulan Juni 1920, Haganah telah didirikan. Haganah ialah sebuah organisasi rahasia yang beranggota kelompok-kelompok pertahanan lokal dan kebanyakan di perkampungan. Kekacauan yang dilakukan pihak Arab membentuk suatu perubahan organisasi terhadap posisi Haganah. (1) Institusi ini menjadi satu organisasi besar yang mengelilingi hampir semua orang pemuda di kampung. Selain itu, banyak anggotanya berasal dari kota. (2) Mereka memulai program latihan lengkap untuk anggota-anggota, mengadakan kursus latihan pegawai. (3) Mendirikan pusat senjata yang mana senjata tangan diharapkan tidak berasal dari Eropa. (4) Secara serentak dasar-dasar pengetahuan dan pembuatan senjata telah dimulai (http://www.us-israel.org).

Gerakan Histadrut dan Haganah membuat rencana meningkatkan peran wanita sebagai pekerja ladang di daerah-daerah pertanian Yahudi. Penambahan peran wanita di sektor pertanian berdasarkan pada pemikiran bahwa kaum laki-laki wajib dilibatkan sebagai anggota gerakan bawah tanah. Tujuannya untuk meningkatkan tekanan terhadap penduduk Palestina yang jumlahnya lebih banyak dari kaum Yahudi. Gerakan ini mewajibkan kepada kaum Yahudi membantu dan menjaga stabilitas di Yishuv. Bahkan mereka diwajibkan menjalankan kontrol dan bersedia melakukan serangan secara gerilya. Atas dasar alasan-alasan inilah, peran kaum wanita sangat diperlukan dalam rangka mempertahankan Yishuv.

Tahun 1920 penduduk Palestina melakukan 
serangan terhadap kampung-kampung Yahudi di Jerusalem dan tahun 1921 terjadi lagi di Jaffa (Robert B. Asprey, 975:844). Serangan yang dilakukan masyarakat Palestina mendapat balasan dari Haganah. Gerakan bawah tanah Yahudi melakukan pembalasan pada malam hari yang diberi nama Special Night Squad (Robert B. Asprey, 975:844) pasukan malam ini didirikan khusus untuk melakukan serangan dan teror terhadap penduduk Palestina.

Pada bulan Agustus tahun 1929, terjadi pertentangan antara penduduk Palestina dan Yahudi di daerah Jerusalem, Hebron, dan Safat sebagai akibat tumbuhnya perasaan anti Yahudi. Tetapi gerakan bawah tanah tidak berdiam diri, mereka melakukan perlawanan. Tidak lama kemudian, gerakan bawah tanah berusaha mendatangkan kaum Yahudi dari daratan Eropa. Tujuannya supaya Yishuv-Yishuv yang masih kosong dapat dipenuhi pendatang Yahudi.

Perkembangan organisasi Zionis pada tahun 1940. an lebih banyak melakukan konsolidasi. Konsolidasi dimaksudkan untuk menarik semua kaum Yahudi Eropa datang ke Palestina. Terutama orang-orang yang pernah terlibat dalam Perang Dunia I. Mereka yang memiliki pengalaman perang bisa menjadi pasukan Yahudi dan langsung di antar ke Palestina. Tujuannya untuk memperkuat kekuatan Yahudi melawan warga Palestina. Bahkan Herbeth Samuel yang bertugas sebagai Utusan Kerajaan Inggeris di Jerusalem dipaksa organisasi Zionis membantu mendatangkan kaum Yahudi ke Palestina (Elia Kedorie and Sylvia G. Haim, 1982:61).

Setelah jumlah mereka meningkat, kaum Yahudi di Palestina sudah berani memberi identitas terhadap diri mereka sebagai pengawal dan bekerja sebagai mata-mata (Richard Deacon, 1977:21). Mereka berperan melakukan proteksi terhadap perkampungan Yahudi dan menghindari ancaman serangan dari penduduk Palestina. Sikap kolektif yang dilakukan para pengawal ini bermanfaat menjamin moshava (kampung yang terdapat pendatang baru Yahudi).

Sebaliknya, penduduk Palestina membuat slogan Itbahu al yahud (slaughter the Jews) dan Falastin bladna wa al yahud clabna (Palestine is our land and the Jews our dogs) (Zeev Schiff and Raphael Rothstein, 1972:34). Ancaman datang dalam berbagai bentuk, seperti individu dan organisasi yang di sudah di organisir (www.us-Israel.org). Aktivitas kaum Yahudi bertujuan untuk membangun negara dan kemudian menjadi tanah air kaum Yahudi (www.jajz.ed.org.il).

Aktivitas Hashomer dan Haganah sejalan dengan tekanan Jerman terhadap kaum Yahudi. Tindakan tentara Nazi Jerman mengusir dan membunuh kaum Yahudi mendorong kedatangan kaum Yahudi ke Palestina. Usaha kaum Yahudi keluar dari Eropa tidak dapat ditahan karena sebagian dari mereka menderita akibat dimasukkan ke dalam penjara Ausewitz. Keadaan ini membawa implikasi jumlah pendatang Yahudi ke Palestina terus bertambah (The Middle East Journal, Vol. 54 2000). Kedatangan kaum Yahudi ke Palestina dilakukan secara besar-besaran menggunakan kapal laut yang di kawal Haganah. Semua kapal-kapal yang membawa kaum Yahudi bertuliskan Zionist. Mereka datang ke Palestina menggunakan berbagai jalan dan yang paling banyak menggunakan kapal laut. Di tengah hiruk-pikuk mendatangkan kaum Yahudi, Haganah membangun secret network dengan pemimpin Eropa dan Amerika Serikat. Tujuannya supaya mereka mendapat kemudahan dan mendapatkan kiriman senjata untuk mempertahankan perkampungan Yahudi (Nadav Safran, 1978:45).

Di balik kekuatan organisasi Yahudi, ternyata terdapat keretakan di dalam gerakan bawah tanah. Haganah B bekerja sama dengan angkatan muda Jabotinsky bersatu membentuk satu gerakan bawah tanah yang disebut dengan Irgun Zvai Leumi (National Military Organizations). Gerakan ini dipimpin oleh David Raziel, (Amos Perlmutter, 2000:371). Selama masa pembentukannya, Irgun Zvai Leumi melakukan tekanan terhadap Inggeris.

Oleh karena itu Haganah membuat strategi menjaga keamanan dan keselamatan perkampungan, rumah dan fasilitas yang dimiliki kaum Yahudi. Haganah secara berani memperluas lahan tanah Yahudi dengan memaksa penduduk Arab keluar dari daerah Arab di Palestina. Cara ini berbeda dengan sebelumnya yang biasa dilakukan dengan membeli tanah.

Pada tahun 1930-an penduduk Yahudi yang dilatih Haganah melakukan perang dengan penduduk lokal. 
Itu sebabnya Haganah menjadi kekuatan dan memainkan peranan mengatur strategi untuk mengamankan Yishuv. Haganah memiliki kekuatan pasukan sebesar 47, 000 terdiri dari laki-laki dan perempuan. Tindakan pengamanan yang dilakukan Haganah dibantu Irgun Zvai Leumi dan Lochamei Herut Yisrael (Nadav Safran, 1978:44).

Secara berulang Haganah melakukan penyerangan terhadap perkampungan Arab di Palestina. Tindakan ini dilakukan untuk memperkecil keberhasilan penyelidikan pihak Palestina terhadap pendatang Yahudi. Akibat tindakan Haganah, kemarahan penduduk Palestina terhadap pendatang Yahudi sewaktu dalam perjalanan ke Yishuv tidak dapat dielakkan. Sebaliknya, tanpa memperdulikan sikap rakyat Palestina, kaum Yahudi terus memperkuat dukungan masyarakat terutama yang bertugas mengawal pendatang Yahudi masuk ke Palestina. Sekalipun mendapat serangan penduduk lokal, mereka terus melakukan perlawanan.

Tahun 1939, terdapat 11,000 pendatang haram Yahudi masuk Palestina, pada tahun 1940 masuk lagi pendatang haram tambahan sebesar 3,900 orang. Mereka terdiri dari anak-anak, perempuan dan laki-laki. Pada tahun 1941 berjumlah 2, 135 pendatang haram Yahudi masuk ke Palestina (Walter Laqueur, 1972:329). Dalam Tabel I terdapat penjelasan mengenai jumlah imigran Yahudi yang datang dari daratan Eropa ke Palestina berdasarkan waktu.

Berdasarkan rekomendasi Kerajaan Inggeris, pada tahun 1940 diadakan sensus di Palestina untuk memantau perkembangan penduduk. Jumlah penduduk Palestina sebesar 1.529.559 dan Yahudi 456.743. Tahun 1946 atau dua tahun sebelum berdirinya negara Israel, kembali diadakan sensus. Jumlah penduduk Palestina sebesar 1.143.336, Yahudi 583.327 dan Kristen 145.063 serta ribuan lainnya seperti Druze, Samaritan dan Hindu. Akibatnya terjadi penurunan jumlah penduduk Palestina. Keadaan ini menyebabkan negara-negara Arab marah terhadap kaum Yahudi dan mereka memberi dukungan kepada perjuangan rakyat Palestina dan tumbuhnya perasaan satu Agama (Tempo, 15-10-1988).

Dengan kemampuan yang dimiliki, kaum Yahudi mengembangkan sebuah institusi yang kompleks menuju berdirinya negara. Untuk tujuan ini kelompok House of Labour (HOL) pimpinan David Ben Gurion menyatukan gerakan imigran dengan gerakan kemerdekaan menjadi satu ideologi yaitu sosialis. Untuk melaksanakan tugas ini HOL membentuk tiga sistem mobilisasi. (i) Para pekerja melakukan mobilisasi ke dalam struktur institusi yang kompleks yaitu Histadrut. (ii) Gerakan Kibbutz mendukung adanya aksi-aksi permukiman pertanian dan (iii) Partai Politik HOL dipimpin oleh Partai Mapai menjadi wakil kepentingan kaum Zionis-Sosialis di dalam Yishuv untuk tujuan menghadapi penentangan Kerajaan Inggeris (Amos Perlmutter, 2000:369).

Tekanan terhadap Inggeris datang dari gerakan bawah tanah Yahudi seperti Irgun Zvai Laumi dan Stern Ganga (Yahya Armajani, 1970:369). Akibat adanya pertentangan antara gerakan bawah tanah Yahudi dan tentara Inggeris, institusi-institusi Inggeris dirusak. Bahkan Hotel King David yang menjadi tempat tinggal warganegara Inggeris, kantor pusat dari divisi kejahatan Inggeris dan Komando Militer Inggeris dirusak Irgun Zvai Leumi dan Lehi (http:/www.us-israel.org).

Begitu juga bantuan yang diberikan negara-negara Arab kepada pejuang Palestina ternyata tidak banyak membantu. Peristiwa Deir Yasin yang terjadi pada tanggal 7 April 1948 di mana Irgun Zvai Leumi bersama Lehi melakukan serangan secara sistematis terhadap perkampungan Palestina di Deir Yasin dekat Jerusalem berhasil membunuh 240 penduduk Palestina (Joseph Heller, 1995:207). Dalam peristiwa ini, pihak Jordan berusaha menekan kaum Yahudi tetapi David Ben Gurion mengelak dari tuduhan itu. Di balik peristiwa itu, David Ben Gurion melakukan manuver politik dengan menyatakan penyesalan terhadap serangan pembunuhan di Deir Yasin dan mengirimkan telegram permohonan maaf kepada Raja Abdullah sebagai pemimpin wilayah Tepi Barat dan Jordan (Joseph Heller, 1995:208).

David Ben Gurion percaya dengan kekuatan tentara Yahudi yang sudah terlatih, mereka bisa memenangi peperangan melawan bangsa Arab dan mereka berkeyakinan dapat mendirikan negara Israel (Tempo, 15-10-1988). Pendapat ini disampaikannya sewaktu 
Tabel I. Negara Asal Imigran dan Pembagian Berdasarkan Tahun

\begin{tabular}{|c|c|c|c|c|c|c|c|}
\hline No & Citizenship & $1919-23$ & 1924-31 & $1932-39$ & $1940-45$ & $1919-45$ & $\%$ \\
\hline 1 & Austria & 497 & 294 & 5,623 & 892 & 7,306 & 2.2 \\
\hline 2 & Bulgaria & 328 & 1,127 & 948 & 2,257 & 4,660 & 1.4 \\
\hline 3 & Czechos & 112 & 363 & 4,779 & 1,181 & 6,435 & 1.9 \\
\hline 4 & England & 180 & 173 & 806 & 89 & 1,248 & 0.4 \\
\hline 5 & Germany & 469 & 660 & 35,980 & 2,022 & 39,131 & 11.7 \\
\hline 6 & Greece & 158 & 696 & 5,280 & 797 & 6,931 & 3.1 \\
\hline 7 & Hungary & 291 & 230 & 1,107 & 1,297 & 2,925 & 0.9 \\
\hline 8 & Italy & 37 & 57 & 556 & 559 & 1,209 & 0.4 \\
\hline 9 & Latvia & 401 & 858 & 3,212 & 86 & 4,557 & 1.4 \\
\hline 11 & Lithuania & 901 & 3,014 & 5,208 & 180 & 9,303 & 2.8 \\
\hline 12 & Poland & 9,158 & 37,387 & 83,847 & 6,833 & 137,225 & 40.9 \\
\hline 13 & Romania & 1,404 & 3,739 & 9,548 & 6,474 & 21,165 & 6.3 \\
\hline 14 & USSR & 13,363 & 14,636 & 2,473 & 634 & 30,836 & 9.2 \\
\hline 15 & Yugoslavia & 145 & 136 & 702 & 746 & 1,729 & 0.5 \\
\hline 16 & Iran & 197 & 865 & 489 & 176 & 1,727 & 0.5 \\
\hline 17 & Iraq & 171 & 2,617 & 124 & 627 & 3,539 & 1,0 \\
\hline 18 & Turkey & 478 & 1,140 & 1,455 & 3,537 & 6,610 & 2.0 \\
\hline 19 & Yemen & 184 & 2,317 & 6,416 & 5,537 & 14,454 & 4.3 \\
\hline 20 & USA & 601 & 1,158 & 4,621 & 16 & 6,396 & 1.9 \\
\hline 21 & Other Countries & 886 & 882 & 6,704 & 2,037 & 10,449 & 3.1 \\
\hline 22 & Stateless & - & - & 4,132 & 4,616 & 8,748 & 2.6 \\
\hline 23 & Unspecified & 5,140 & 1,146 & 2,087 & 110 & 8,483 & 2.5 \\
\hline 24 & Total & 35,101 & 73,435 & 186,097 & 40,433 & 335,066 & 100.0 \\
\hline
\end{tabular}

Source:Gertz, (ed) Statistical Handbook of Jewish Palestine, 1947.

Dalam buku Dan Horowitz and Mosse Lissak, Origin of the Israeli Polity, (Chicago:University of Chicago Press, 1978), hlm. Appendix 2

berlangsung diskusi yang dihadiri oleh ketua-ketua partai politik untuk menentukan rencana mendirikan negara Yahudi di Palestina. Tidak lama berselang, tepatnya pada tanggal 14 Mei 1948, Jewish Agency memanfaatkan konflik antara kaum Yahudi dengan penduduk Palestina dan berakhirnya mandat Inggeris di Palestina untuk mendirikan negara Israel.

\section{PEMBENTUKAN PERTAHANAN}

Pada tahun 1948 menjadi turning point Israel untuk membangun hubungan antara politik dan militer menjadi suatu kekuatan (Yoram Peri, 1983:57). Proses pendirian institusi pertahanan dan keamanan dilakukan secara berangsur-angsur menurut keadaan yang terjadi di sekitar. Setelah negara Israel didirikan, tiga minggu berikutnya Haganah B dan Palmach bersatu dan berganti menjadi Israel Defense Force.

Sistem pertahanan Israel dikembangkan untuk menjaga keamanan dan stabilitas negara. Supaya pasukan pertahanan Israel memiliki (a) rasa kebanggaan pada bangsa (b) pengabdian terhadap prinsip sosialisme dan gerakan Kibbutz (c) disiplin diri (d) pendidikan kepemimpinan (Amos Perlmutter, 2000:374).

Pendirian negara Israel tidak dapat diabaikan dari pengalaman -Israel dan sebelumnya disebut - pasukan Yahudi di dalam menjalankan Perang Gerilya.

"Pertahanan dan Keamanan" menjadi perhatian utama Israel yang ditujukan terhadap penduduk, pemukiman dan petani (Michael Howard, 1965:338).

Konsep dasar gerakan bawah tanah yang pernah 
dijalankan secara profesional dan masih bisa dikenali adalah Unit Haganah B dan Palmach. Kedua gerakan bawah tanah menjalankan pengintaian dan seranganserangan ke kawasan Arab melalui sistem managemen militer profesional. Haganah berperan sebagai tulang punggung militer Israel disebabkan mempunyai unitunit yang dapat memainkan peran sebagai pasukan khusus yaitu Haganah B. Pasukan ini terdiri dari dua kekuatan yaitu Krav Maga dan Histadrut. Keduanya disiapkan sebagai kekuatan utama militer Israel.

Dengan kekuatan yang dipunyai, Perdana Menteri Israel berusaha membentuk suatu badan pertahanan yang disegani lawan maupun kawan yaitu Israel Defense Force (IDF) dan dalam bahasa Ibrani disebut “Tzva Haganah le-Yisra'el”. Dalam rencana kegiatannya, IDF akan melibatkan peran kekuatan militer berdasarkan Krav Maga dan Histardut (www. haganah.com). Krav Maga merupakan suatu institusi pertahanan berdasarkan pada kemampuan individu dalam mempertahankan diri. Kemampuan dari Krav Maga khusus untuk penggunaan berbagai bentuk senjata dan "hand to hand system". Histadrut turut serta menjadi komponen penting dalam pertahanan. Tangan digunakan sebagai alat untuk mengalahkan lawan dalam Perang Gerilya. Kedua unsur kekuatan dapat menjadi Israel Martial Arts karena konsep kekuatan ini lebih menggunakan sistem pertahanan yang biasa digunakan dalam perang terbuka (www.haganah.com).

Berdasarkan pemikiran filsafat, sistem pertahanan Israel menggabungkan antara kekuatan dengan sejarah bangsa Yahudi:

Barangkali siapa yang memberkati nenek moyang kami, Abraham, Isaac dan Jacob menyukai seorang tentara yang didirikan Israel yang bertugas menjaga tanah tuhan dan kota-kota tuhan kita. Dari tepi pinggir Libanon ke Padang Pasir Mesir dan dari laut mati ke tepi lautan yang melawan kita. Semoga Isaac yang selalu menyelamatkan dan menyayangkan tentara kita dari semua rasa sengsara dan kesedihan, dari perasaan dan penyakit, dari cara yang tidak mengenal kekalahan terhadap mereka yang kami bantu, dan semoga menghiasi mereka dengan mahkota keselamatan dan baju jubah kemenangan, demikian, semoga jubah dapat ditepati:'Tuhan dan anaknya berjalan untuk berjuang melawan musuh anaknya, untuk kemenangan anaknya", sekarang biar kita membalas. Oleh karena itu, tujuan pengamanan yang dilakukan IDF sekarang adalah untuk mempertahankan daerah dan kedaulatan Israel, menghalangi semua musuh dan membasmi semua keganasan yang dapat mengancam kehidupan kita setiap hari (www.ahavet-israel.com).

Dengan memperhatikan tujuan di atas tindakan pemerintah Israel akan terlihat lebih jelas terutama bila dikaitkan dengan kebijakan dan tujuan IDF.

Tujuan dari IDF di bidang keamanan adalah mempertahankan integrasi kawasan dan kesejahteraan dari negara Israel dan mempertahankan negara terhadap serangan teroris yang bisa mengancam kehidupan Israel setiap hari (www.ahavet-israel.com).

IDF menjadi institusi pertahanan dalam dan luar negeri yang berperan menjaga stabilitas negara secara menyeluruh. Berdasarkan struktur pemerintahan, Perdana Menteri dan Menteri Pertahanan berada di tangan satu orang. Di bawah Menteri Pertahanan terdapat seorang "Chief of Staff " yang menjadi pemimpin IDF. Di bawah koordinasi Chief of Staff, Israel memainkan peranan penting dan strategis terhadap pertahanan dan keamanan negara. Dapat dikatakan dari segi struktur IDF merupakan institusi strategis. Pembentukan IDF mempunyai tiga misi yaitu:

Untuk mempertahankan kehidupan dan kedaerahan, kedaulatan negara Israel. Untuk melindungi penduduk Israel. Untuk melawan teroris yang mengancam mereka (www.bromleyshul.org.uk).

Terkait dengan misi yang diemban IDF, Israel seakan tidak mempunyai pilihan lain. Dilihat dari aspek geografi berada di satu kawasan yang berbatasan dengan negara-negara Arab. Artinya bahwa negaranegara yang berada di sekitarnya menjadi musuh sekaligus ancaman Israel. Ancaman ini erat hubungannya dengan keberhasilan Israel melakukan pendudukan terhadap kedaulatan Arab seperti di Tepi Barat, Jerusalem, dan beberapa kawasan kecil di daerah 
Gaza. Oleh karena itu Israel kemudian merancang suatu kebijakan keamanan dan stabilitas negara yang dapat dilakukan setiap hari.

Kebijakan IDF telah menjadi alat untuk mengawal pelaksanaan kebijakan negara seperti mempertahankan, mewujudkan penempatan perukim baru di tepi perbatasan guna menolong beratus-ratus ribu pendatang baru yang akan dimasukkan IDF atau membangun strategi dialog dengan berbagai negara, termasuk Amerika Serikat tetapi juga mengontrol daerah yang telah ditaklukkan pendahulunya (Ze'ev S. Lustick, Middle East Journal, Volume 53. 1999).

Untuk tujuan menjaga stabilitas di bidang pertahanan, (a) Setiap waktu peperangan bisa terjadi antara Israel berhadapan dengan lebih dari satu negara Arab (b) setiap waktu Israel harus menyiapkan kekuatan yang bisa dikerahkan untuk melawan negara-negara Arab (Baruch Kimmerling dalam Mosse Lissak, 1958:134). Semua masa lalu yaitu sewaktu terjadi peperangan Israel tidak melakukan operasi tentara secara penuh, akan tetapi sekurang-kurangnya satu negeri. Negara Arab tidak mau mengakui adanya hak Israel dan seterusnya membuat peperangan dengan cara lain (misalnya melalui ekonomi, politik, atau diplomatik) yang menyatakan pertentangan terhadap masyarakat Israel (Yigal Allon dalam Mosse Lissak, 1958:13).

Gambaran di atas menjadi dasar kebijakan Israel sejak tahun 1948 sampai masuknya Perang Arab-Israel tahun 1967. Setelah masa-masa kritis, menjelang dan brakhirnya peperangan, ide di atas dilanjutkan sampai sekarang. Konsep perluasan wilayah yang dikembangkan Israel tidak terlepas dari peran dan kreasi IDF. Itu sebabnya andil IDF memainkan peran penting menjaga stabilitas Israel.

\section{PERTAHANAN MENYELURUH}

Setiap negara di dunia mesti mempunyai suatu sistem pertahanan. Berdasarkan pada keadaan geografis dan kemampuan militer, negara biasanya melakukan kreasi untuk meningkatkan pertahanan menjadi sebuah kekuatan. Sistem pertahanan negara penting disampaikan karena setiap negara harus mempunyai kemampuan untuk mempertahankan dan membela negara. Dengan cara inilah negara dapat meminimalisasi ancaman baik dari dalam maupun luar.

Negara menjadi suatu institusi dan berperan mengatur bagaimana kebijakan yang harus dilakukan guna mempertahankan dan menjaga keamanan dari berbagai bentuk ancaman baik yang langsung maupun tidak langsung. Artinya semua ancaman yang datang perlu dibuat rumusan bagaimana bentuknya agar dapat di respon kembali. Secara umum kemampuan negara melakukan respon terhadap berbagai ancaman sudah dirumuskan dalam satu kekuatan yang disebut dengan sistem pertahanan dan keamanan.

Menurut konsep pertahanan, dapat dikatakan bahwa sistem pertahanan Israel adalah total defense (pertahanan menyeluruh). Pertahanan menyeluruh yang dipakai melibatkan semua elemen warga negara terutama yang berada di dalam negeri. Dengan kekuatan ini, maka sistem pertahanan menyeluruh dapat bergerak lebih aktif lagi sekiranya terjadi keadaan darurat.

Sebagai negara yang memiliki ancaman sangat besar, Israel harus siap terhadap segala bentuk ancaman. Baik ancaman yang datang dari individu, kelompok bahkan negara. Oleh karenanya, Israel menganut sistem pertahanan menyeluruh berdasarkan pada (1) sejarah berdirinya negara, (2) geografi dan (3) kawasan di sekitarnya. Tiga faktor ini turut menguatkan niat Israel menjadi negara yang harus mengambil perhatian dalam masalah pertahanan dan keamanan negara. Sistem pertahanan menyeluruh menjadi kebijakan prioritas untuk mempertahankan kewibawaan nasional dan menghindari ancaman dari luar baik dari negara besar maupun kecil.

Israel sekalipun dapat digolongkan sebagai negara kecil tetapi sistem pertahanan yang dipunyai mampu memberi jaminan terhadap masyarakat dan negara secara menyeluruh. Perlu ditambahkan pula sistem pertahanan menganut pola ofensif dan tanpa mengenal kompromi. Menurut pendapat Ken Booth, dikaitkan dengan pertahanan, mengatakan bahwa bidang kajian ini mempunyai pandangan, perhatian dan penjelasan terhadap dimensi militer (Ken Booth and Eric Herring, 1994:21). Terdapat lima bidang yang terkait langsung dengan kajian strategis termasuk di dalamnya pertahanan yaitu ancaman, strategi, penggunaan 
kekuatan militer, pencegahan dan peperangan.

Keamanan dikaitkan dengan dua bidang kajian yaitu kebijakan negara dan sistem pengamanan negara menjadi komponen utama Israel. Keduanya mempunyai cara kerja yang berbeda tetapi tujuannya sama yaitu keamanan dan pertahanan negara. Kebijakan negara lebih banyak membicarakan kemampuan negara dalam merumuskan isu-isu nasional. Sistem pengamanan terkait dengan tinggi atau rendahnya tingkat ancaman terhadap negara Israel.

Penggunaan Konsep strategis yang dikembangkan Israel mampu menjadi tulang punggung keamanan negara. Berdasarkan pendapat Ken Booth bahwa tindakan negara dilihat dari persepsi pertahanan harus memiliki kekuatan. Kekuatan pertahanan Israel terdiri dari lima elemen pertahanan yaitu:(i) pertahanan psikologi (ii) pertahanan sosial (iii) pertahanan ekonomi (iv) pertahanan masyarakat dan (v) pertahanan ketentaraan (www.mindef.gov.sg).

Dari kelima elemen kekuatan pertahanan, Israel melakukan pengamanan setiap hari terhadap masyarakat dan negara. Untuk mewujudkan rasa aman terhadap masyarakat dilakukan di setiap kawasan yang terdapat penduduk dan aktivitas masyarakat baik di kampung-kampung maupun di kota-kota utama Israel. Sebagaimana disampaikan oleh Martin van Creveld:

Pertama, berarti setiap hari harus ada kemampuan keamanan dari individu terhadap warga Israel untuk bekerja, berjalan dan tidur tanpa dibom oleh teroris. Kedua, keamanan berarti melakukan sesuatu terhadap ancaman yang dirasakan Israel sebagai sebuah negara dan sebuah bangsa (Martin Van Creveld, 1984:115).

Sistem keamanan dilakukan setiap waktu karena Israel menghadapi ancaman baik dari dalam maupun luar. Menurut pendapat Mose Dayan tentang konsep keamanan yang pernah digunakan dan sampai sekarang masih digunakan adalah:

Kami adalah satu generasi penduduk tanpa topi atau senapang. Kami tidak boleh menanam pokok atau membangun rumah. Biar kami jangan takut melihat musuh dengan kepekaan kehidupan beratus dan beriburibu Arab di sekeliling kami. Biar kami jangan memalingkan pemandangan kami, kalau-kalau dapat melemahkan tangan kami. Terimalah nasib generasi kami. Cuma satu pilihan kami yaitu bersenjata kuat dan tabah, kalau tidak pedang akan jatuh dari tangan kami dan benang kehidupan kami akan diputus Moshe Dayan, 974:240).

Dapat dikatakan bahwa format pertahanan menyeluruh Israel digunakan untuk menggambarkan hubungan antara sejarah perjuangan, sistem masyarakat dan tingkat ancaman. Berdasarkan hubungan ketiganya, Israel melaksanakan pertahanan menyeluruh yang ofensif. Tindakan ofensif menjadi dasar kebijakan yang dapat motivasi tentara Israel bergerak lebih cepat sesuai tujuan dan misi pembentukan IDF. Itu sebabnya agenda negara Israel menurut ketiga kekuatan yaitu kebijakan, tujuan dan misi adalah kemenangan. Ketiganya bersatu kemudian diarahkan untuk menambah kaum Yahudi, memperkuat kekuatan dan menjaga stabilitas. Kalau luas negara sudah tidak lagi memenuhi untuk menampung jumlah pendatang Yahudi yang terus masuk ke Israel, maka strateginya adalah mengambil tanah yang masih menjadi tempat tinggal masyarakat Palestina dan dijadikan bagian dari negara Israel. Sekalipun proses yang dilakukan harus dengan berperang. Pada konteks ini, tanah sudah menjadi bagian dari ideologi Israel. Suatu fakta yang tidak dapat dipertentangkan mengenai kekalahan beberapa kawasan notabene dapat menjadi kawasan negara Palestina telah berpindah ke Israel (Abdul Rahman, Jurnal Antar Bangsa, Vol 2. 2003).

\section{TANTANGAN KONTEMPORER}

Dalam konteks sekarang, harus disadari tekanan terhadap Israel dari warga Palestina tidak dilakukan sekadar menghukum Israel. Melainkan sebagai balasan atas tindakan brutal tentara Israel terhadap penduduk Palestina. Di dalam logika Israel dan sebagian besar masyarakat Palestina bahwa serangan harus dibalas dengan serangan. Kematian harus dibalas dengan kematian. Kalimat ini bukan tidak disadari, tetapi inilah anggapan yang berkembang dan menjadi garis kebijakan kedua pihak. Dalam konteks mewujudkan perimbangan kekuatan antara Palestina-Israel. Tidak heran jadinya, tindakan saling serang antara pemerintah Israel dan masyarakat Palestina menjadi potret buram perkembangan politik di Timur Tengah terkini. Secara 
arogan Israel menolak membahas kehadiran tentaranya di daerah pendudukan. Menurut Israel, kehadiran tentaranya sangat diperlukan untuk mengamankan warga Israel.

Nyatanya fakta yang terjadi bahwa kehadiran tentara Israel malah merusak suasana perdamaian. Tentara Israel lebih banyak mencetuskan konflik ketimbang mewujudkan perdamaian. Artinya Israel masih beranggapan bahwa kebijakan pendudukan menjadi kepentingan Israel dan harus dilakukan untuk tujuan menjaga keamanan wilayah sekaligus mencetuskan konflik baru yang dapat merusak rencana perdamaian. Tindakan ini tidak sulit dilakukan. Hanya dengan menempatkan pasukan dan didukung satuan Tank, konflik berkembang ke arah peperangan.

Sejujurnya apa yang terjadi bukan lah skenario biasa Israel. Melainkan suatu cara untuk melakukan politik pendudukan. Dengan cara menghancurkan satupersatu rumah penduduk Palestina yang dianggap membangkang terhadap kebijakan Israel. Lalu, sedikit demi sedikit Israel berusaha mengurangi jumlah penduduk Palestina dari kantong-kantong pendudukan terutama di wilayah Tepi Barat. Menurut Israel, menempatkan perkampungan Yahudi di dekat kantong-kantong Palestina menjadi momentum untuk memancing kemarahan warga Palestina. Setelah mereka marah, tentara Israel siap mengamankan daerah dengan kekerasan (Riau Mandiri, 17-6-2003). Serangan

berbuntut kematian menjadi bagian terpenting untuk mengamankan setiap jengkal tanah di wilayah pendudukan.

Tidak heran jadinya tiap tahun jumlah pemukiman Yahudi terus membengkak. Bahkan lima tahun ke depan diperkirakan permukiman yang ada sudah tidak cukup untuk menampung pendatang Yahudi dan keluarga baru yang ingin membangun rumah tangga.

Sebagai alat justifikasi, klaim historis bahwa Tepi Barat sebagai wilayah Yahudi menjadi simbol agama dan politik untuk tetap menduduki wilayah Tepi Barat. Alasannya disana pernah berdiri dua kerajaan Yahudi yaitu Yudae dengan Ibu kotanya Jerusalem dan Samaria dengan Ibu kotanya Syekem (sekarang Nablus). Dari sudut ekonomi, kawasan laut Mati menjadi objek wisata sebagai penghasil bahan kosmetik terbaik di dunia. Tidak heran jumlah turis yang cukup besar ke wilayah laut mati berperan mendatangkan keuntungan dalam jumlah besar bagi ekonomi Israel.

Sedangkan persepsi geografis bahwa penguasaan terhadap dataran Tinggi Golan sebagai sumber air harus dikontrol dari wilayah Tepi Barat. Artinya wilayah Tepi Barat menjadi daerah strategis untuk mengatur perairan ke kawasan-kawasan Israel lainnya. Tanpa ada penguasaan terhadap Tepi Barat rasanya sukar Israel dapat melangsungkan kehidupan terlepas dari permasalahan air. Artinya persoalan air menjadi masalah hidropolitik bila Israel terpaksa harus melepaskan kawasan Tepi Barat dan masuk ke dalam negara Palestina.

Soal lain yang perlu diperhatikan adalah tidak seriusnya Israel melakukan perundingan-perundingan damai dan terakhir mengenai Peta Jalan Damai, rasanya mustahil Israel melepas daerah yang sudah dikuasinya. Terlepas dari itu, Perang Enam Hari tahun 1967 erat hubungannya dengan politik pendudukan yang dilakukan Israel. Artinya Israel merencanakan agar mendapatkan tambahan luas wilayah dan bukan menguranginya.

Kecuali tekanan dari negara-negara besar terutama Amerika Serikat secara kolektif benar-benar dapat menutup ruang gerak Israel. Namun adanya kekuatan Lobby Yahudi yang begitu besar di Amerika Serikat sulit dapat melaksanakan rencana perdamaian. Mengingat kemampuan politik dan ekonomi kaum Yahudi cukup besar dan sangat berpengaruh terhadap ekonomi Amerika Serikat bahkan dunia.

\section{KESIMPULAN}

Kiranya gambaran di atas memperlihatkan secara nyata mengenai dasar-dasar pembetukan gerakan bawah tanah dan Israel defense Force. Pada tahun 1948 menjadi turning point Israel untuk membangun hubungan antara politik dan militer menjadi suatu kekuatan. Keduanya menjadi satu-kesatuan yang diikat sejarah memperlihatkan hubungan yang signifikan antara kebijakan, tujuan dan misi di satu sisi dengan keinginan pemerintah untuk memperluas wilayah guna menambah pemukiman Yahudi dalam jumlah besar. 
Melihat kecenderungannya, Israel berusaha memancing negara-negara Arab untuk berperang dengannya.

Karena melalui perang suatu wilayah di sebuah negara dengan mudah bisa diduduki dan dialihkan statusnya. Untuk mendapatkan tanah, maka formasi militer, ideologi dan peranan strategi menjadi kekuatan kunci yang harus dimasukkan dalam sistem pertahanan menyeluruh Israel.

Disinilah arti penting tindakan ofensif yang menjadi dasar kebijakan pertahanan Israel dengan mengedepankan pertahanan menyeluruh. Tanpa ada tindakan ofensif, rasanya Israel sukar melakukan tekanan yang berdampak terhadap kemenangan Israel dalam setiap peperangan melawan negara-negara Arab. Karena di balik perang, pendudukan atas tanah-tanah Palestina menjadi tujuan utama serangan Israel. Itu sebabnya, dalam perkembangan sekarang Israel lebih suka memilih berperang daripada damai.

Kondisi ini semakin jelas bahwa Israel tidak ingin berdamai dan wilayah Palestina akan terus berkecamuk sampai penduduk Palestina terusir dari wilayah Tepi Barat. Potret buram inilah yang terus menghiasai masa depan Palestina sekaligus masa depan Timur Tengah. Akankah perdamaian tercapai di Timur Tengah kalau Israel terus bersikap ofensif.

\section{REFERENSI}

Asprey, Robert B, War In The Shadows The Guerilla In History, (New York:Double Day \& Company Inc., 1975).

Armajani, Yahya, Middle East:Past and Present, (New Jersey:Prentice Hall, 1970)

Booth, Ken and Herring, Eric, Strategic Studies, (London:Mansell Publishing Limited, 1994).

Bickerton, Ian J, and Klausner, Carla L, A Concise History of The ArabIsraeli Conflict, (Englewood:Prentice Hall:1991).

Dayan, Moshe, Shabtai Teveth, (London:Quartet Books, 1974).

Deacon, Richard, The Israel Secret Service, (London:Hamish Hamilton, 1977).

Heller, Joseph, The Stern Gang:Ideology, Politics and Terror, 19401949, (London:Frank Cass, 1995)

Horowitz, Dan and Lissak, Mosse, Origin of the Israeli Polity, (Chicago:University of Chicago Press, 1978).

Howard, Michael, (ed) The Theory and Practise War, (London:Cassell, 1965).

Ismael, Tareq Y, Politics and Government in the Middle East and North Africa, (Miami:Florida University Press, 1991).

Kedorie, Elia and Haim, Sylvia G, (eds) Palestine and Israel in the $19^{\text {th }}$ and $20^{\text {th }}$ Centuries, (London:Frank Cass, 1982).
Kimmerling, Baruch, Making Conflict A Routine: Cumulative Effects of the Arab-Jewish Conflict Upon Israeli Society, dalam Mosse Lissak, Israel Society and Its Defense, hlm. 134.

Yigal Allon, A Curtain of Sand: Tel Aviv: Hakibbutz Hameuchad, dalam Mosse Lissak, Israel Society and Its Defense (London:Frank Cass, 1984).

Laqueur, Walter, A History of Zionism, (New York:Rinehart and Winston, 1972).

Perlmutter, Amos, Politics And The Military in Israel 1967-1977, (London:Frank Cass, 1978).

, Militer dan Politik, (terjemahan Sahat Simamora), (Jakarta:Rajawali Press, 2000).

Perezt, Don, The Arab-Israel Dispute, (New York:Facts on File Inc., 1996).

Peri, Yoram, Between Battles And Ballots: Israel Military in Politics (Cambridge:Cambridge University Press, 1983).

Safran, Nadav, Israel The Embattled Ally, (Boston:The Belknap Press of Harvard University Press, 1978).

Sayigh, Rosemary, Palestinians:From Peasants to Revolutionaries, (London:Zed Press, 1979).

Schiff, Zeev and Rothstein, Raphael, Fedayeen:The Story of the Palestine Guerillas, (London: Vallentine-Mitchell, 1972).

Van Creveld, Martin, The Making of Israel's Security dalam Stephanie G. Neuman, Defense Planning in Less-Industrialized States, (Lexington:Lexington Books, 1984)

\section{Jurnal}

Lustick, Ze'ev S. "Fifty Year of Israeli Security:The Central Role of The Defense System" Middle East Journal, Volume 53. No. 3, Summer 1999.

Miriam Joyce, "The Birth of Israel, 1945-1949", The Middle East Journal, Vol. 54 Number 4 Auttumn 2000.

Rahman, Abdul, “Perjuangan Rakyat Palestina Melawan Israel:Sebuah Sketsa Terhadap Kebangkitan Gerakan Islam di Indonesia Mendukung Pendirian Negara Palestina", Jurnal Antar Bangsa, Vol. 1 No 2 Juli 2003.

\section{Media Cetak}

Riau Mandiri, 17 Juni

Tempo, 15 Oktober 1988

\section{Internet}

www.us-israel.org/jsource/Society_\&_Culture/artzi.html. www.us-israel.org/jsource/History/haganah.html www.us-Israel.org/jsource?History/pail.html. www.jajz.ed.org.il/100/maps/. www.us-israel.org/jsource/History/King_David.html www. haganah.com www.ahavet-israel.com/ahavet/erezt/army.asp wnw.bromleyshul.org.uk/Mission_of_the_IDF.htm www.mindef.gov.sg. 